\title{
NÍVEIS CRÍTICOS E TÓXICOS DE BORO EM SOLOS DE PERNAMBUCO DETERMINADOS EM CASA DE VEGETAÇÃO ${ }^{(1)}$
}

\author{
Júlio César Patrício de Souza Lima ${ }^{(2)}$, Clístenes Williams Araújo do \\ Nascimento $^{(3)}$, Júlio Guilherme da Costa Lima ${ }^{(2)} \&$ Mário \\ de Andrade Lira Junior ${ }^{(3)}$
}

\begin{abstract}
RESUMO
Pesquisas sobre a disponibilidade de B em solos são necessárias para avaliar o comportamento das culturas sob diferentes teores disponíveis desse elemento no solo. Com essa finalidade, foi realizado um experimento em casa de vegetação para avaliar a resposta de milho (Zea mays) a doses de boro $\left(0,2,4,6\right.$ e $\left.12 \mathrm{mg} \mathrm{dm}^{-3}\right) \mathrm{em}$ dez solos de Pernambuco. O B disponível foi determinado por três extratores: água quente, ácido clorídrico $0,05 \mathrm{~mol} \mathrm{~L}^{-1}$ e Mehlich-1. Foram ainda determinados os níveis críticos (90 e 95 \% da produção máxima de matéria seca) e tóxicos (equivalente à redução de 10 \% da produção máxima) nos solos e na planta, além da descrição de sintomas de toxidez de $B$ em milho. Os resultados demonstraram que os níveis críticos e tóxicos de $B$ nos solos variaram de 0,4 a $2,3 \mathrm{mg} \mathrm{kg}^{-1}$ e de 1,8 a $8,3 \mathrm{mg} \mathrm{kg}^{-1}$, respectivamente. Em plantas de milho, os níveis críticos variaram de 13,8 a $129,6 \mathrm{mg} \mathrm{kg}^{-1}$, enquanto teores tóxicos foram obtidos entre $43,3 \mathrm{e} 372,2 \mathrm{mg} \mathrm{kg}^{-1}$. O extrator que obteve a melhor correlação com o teor de $\mathrm{B}$ na planta foi o $\mathrm{HCl}$ $0,05 \mathrm{~mol} \mathrm{~L}^{-1}$, seguido pelo Mehlich-1 e pela água quente. A disponibilidade do $\mathrm{B}$ no solo pelo extrator $\mathrm{HCl}$ e os teores de $\mathrm{B}$ na folha foram afetados negativamente pelo aumento no teor de argila e matéria orgânica dos solos. Os solos que apresentaram plantas com maior teor de B no tecido vegetal mostraram sintomas mais graves de toxidez, fator associado à maior disponibilidade de boro em solos com textura mais arenosa e, ou, baixos teores de matéria orgânica.
\end{abstract}

Termos de indexação: disponibilidade de boro, toxidez de boro, micronutrientes.

\footnotetext{
(1) Parte da Tese de Mestrado do primeiro autor apresentada ao Programa de Pós-Graduação em Ciência do Solo da Universidade Federal Rural de Pernambuco - UFRPE. Recebido para publicação em julho de 2005 e aprovado em janeiro de 2007.

${ }^{(2)}$ Mestrando da Universidade Federal Rural de Pernambuco - UFRPE. CEP 52171-900. Recife (PE). E-mail: juliocpsl@yahoo.com

(3) Professor Adjunto do Departamento de Agronomia, UFRPE. Pesquisador do CNPq. E-mail: cwanascimento@yahoo.com
} 


\title{
SUMMARY: CRITICAL AND TOXIC BORON LEVELS IN CORN PLANTS AND SOILS OF PERNAMBUCO, BRAZIL
}

\begin{abstract}
Research on $B$ availability in soils is essential to assess the crops response to different concentrations of available $B$ in soils. A greenhouse experiment was carried out aiming at studying the corn plant (Zea mays) response to $B$ doses $\left(0,2,4,6\right.$, and $\left.12 \mathrm{mg} \mathrm{dm}^{-3}\right)$ applied to ten soils from the state of Pernambuco, Brazil. Available $B$ was assessed by three extractants: hot water, $\mathrm{HCl} 0.05 \mathrm{~mol} \mathrm{~L} \mathrm{~L}^{-1}$, and Mehlich-1. The critical and toxic levels were determined in soils and plants. Additionally, $B$ toxicity symptoms in corn plants were recorded. Results showed that the critical and toxic $B$ levels in soils ranged from 0.4 to $2.3 \mathrm{mg} \mathrm{kg}^{-1}$ and from 1.8 to $8.3 \mathrm{mg} \mathrm{kg}^{-1}$, respectively. For corn plants, the critical levels varied from 13.8 to $129.6 \mathrm{mg} \mathrm{kg}^{-1}$ and the toxic levels from 43.3 to $372.2 \mathrm{mg} \mathrm{kg}^{-1}$. $\mathrm{HCl}$ $0.05 \mathrm{~mol} \mathrm{~L}^{-1}$ was the extractant that best correlated with the B plant content, followed by Mehlich-1 and hot water. Both available $B$ assessed by $\mathrm{HCl}$ and $\mathrm{B}$ plant contents were inversely related to clay and organic matter concentrations in soils. Soils on which plants with highest $B$ contents grew presented the most acute $B$ toxicity symptoms. This was associated with sandy and low organic matter soils.
\end{abstract}

Index terms: Boron availability, boron toxicity, micronutrients.

\section{INTRODUÇÃO}

O boro (B) participa de importantes processos fisiológicos nas plantas, como transporte de ácido indolacético, atividade da ATPase (Goldbach et al., 2001), integridade da membrana, síntese da parede celular, metabolismo fenólico, do RNA e de carboidratos, além de respiração e lignificação (Gupta, 1993). A deficiência de B tem provocado perda de produtividade em algumas culturas no Brasil (Mariano et al., 2000) e foi reportada para mais de 130 culturas no mundo (Shorrocks, 1997). Embora menos comum que a deficiência, a toxidez de B tem sido observada em algumas situações. Geralmente, teores tóxicos de $\mathrm{B}$ em solos têm sido associados a problemas de salinidade em regiões áridas. Problemas de toxidez do elemento não ocorrem normalmente em solos agrícolas, a menos que compostos com $\mathrm{B}$ tenham sido adicionados em quantidade excessiva - por exemplo, via água de irrigação ou fertilizantes minerais (Gupta, 1993).

O sintoma visual típico de toxidez de B na maioria das espécies é a queima das folhas, ou seja, clorose e necrose, freqüentemente nas bordas e pontas das folhas mais velhas. Isso reflete a distribuição do B na maioria das plantas, que se acumula, seguindo o fluxo transpiratório (Nable et al., 1997). Deve-se observar, no entanto, que necrose em folhas mais velhas não é o sintoma de toxidez de B em todas as plantas. De forma geral, o B possui baixa mobilidade no floema da maioria das espécies vegetais, com exceção das produtoras de tióis (álcoois de açúcar), que apresentam, diferentemente das demais espécies, sintomas de deficiência em folhas mais velhas e toxidez em tecidos meristemáticos, visto que o B se moveria na planta ligado aos tióis (Gupta, 1993; Römheld, 2001).

No solo, o B é geralmente encontrado em maior quantidade na matéria orgânica, o que sugere a sua maior probabilidade de escassez em solos arenosos. A disponibilidade desse micronutriente depende também do material de origem e da mineralogia, pois reações com óxidos de ferro e alumínio controlam sua solubilidade (Gupta, 1993; Rocha, 1995). Entre os minerais presentes em solos intemperizados, os picos de adsorção máxima encontrados para óxidos cristalinos de $\mathrm{Fe}, \mathrm{Al}$ e caulinita se situam em torno de $\mathrm{pH}$ 7-8 (Goldberg, 1999). Oxidos de Al amorfos alcançam picos de adsorção em pH 6-7 (Goldberg \& Glaubig, 1985). Goldberg \& Forster (1991) destacam ainda que as calcitas apresentam expressiva adsorção de $B$, o que atenua o efeito tóxico do elemento em solos de $\mathrm{pH}$ elevado, como os de regiões semi-áridas, onde a toxidez do Bé mais comum.

Para determinação de níveis críticos de $\mathrm{B}$ em solos, deve-se considerar a capacidade de extração das diferentes soluções utilizadas e suas correlações com os atributos dos solos. Isso conduz a distintos níveis críticos de B quando diferentes extratores, tipos de solos e culturas são avaliados. Por exemplo, Buzetti et al. (1990a) observaram níveis críticos no solo entre 0,11 e $0,23 \mathrm{mg} \mathrm{dm}^{-3}$ de B para soja usando duas doses de calcário em um Latossolo Vermelho-Escuro, enquanto Mariano et al. (2000) encontraram níveis críticos mais elevados, variando de 0,57 a $1,89 \mathrm{mg} \mathrm{dm}^{-3}$, para feijoeiro em solos de várzea. De acordo com Nable et al. (1997), teores de B no solo acima de $5 \mathrm{mg} \mathrm{dm}^{-3}$ são considerados tóxicos para as plantas. Entretanto, Paula (1995) constatou que teores de B de $2 \mathrm{mg} \mathrm{dm}^{-3}$ provocaram redução de crescimento sem sintomas de toxidez em plantas de arroz cultivadas em solos aluviais e hidromórficos. Mariano et al. (2000), em solos de várzea, determinaram teores tóxicos de $\mathrm{B}$ para feijoeiro variando de $1,87 \mathrm{a} 4,65 \mathrm{mg} \mathrm{dm}^{-3}$. Fageria (2000), trabalhando com cinco espécies vegetais em Latossolo Vermelho-Escuro do cerrado, encontrou toxidez de B para soja $\left(5,2 \mathrm{mg} \mathrm{kg}^{-1}\right)$ e milho $\left(5,7 \mathrm{mg} \mathrm{kg}^{-1}\right)$. 
Apesar de alguns relatos de deficiência de B para cana-de-açúcar em solos da Zona da Mata de Pernambuco, dados sobre disponibilidade e toxidez de B em solos do Estado são muito escassos. Nesse sentido, o presente trabalho objetivou determinar os níveis críticos e tóxicos de $\mathrm{B}$ em solos de Pernambuco para plantas de milho, bem como relacionar a disponibilidade de $\mathrm{B}$ com características químicas e físicas dos solos e, ainda, determinar o extrator mais adequado para avaliação da sua disponibilidade.

\section{MATERIAL E MÉTODOS}

Dez classes de solos de duas regiões fisiográficas do Estado de Pernambuco (Zona da Mata e Agreste) com diferentes atributos associados com disponibilidade de $\mathrm{B}$, com destaque para matéria orgânica e argila, foram selecionadas para o estudo: Argissolo Vermelho-Amarelo, Espodossolo Cárbico, Latossolo Amarelo, Nitossolo Vermelho, Gleissolo Háplico, Planossolo Háplico, Neossolo Regolítico, Planossolo Nátrico, Latossolo Vermelho-Amarelo e Argissolo Amarelo. Após localização dos perfis com GPS, procedeu-se à coleta de amostras da camada superficial (0-20 cm), a qual, após passada em peneira de $2 \mathrm{~mm}$, foi caraterizada química e fisicamente (Quadro 1), conforme Embrapa (1997). O teor de B por água quente foi determinado segundo Bataglia (1983). A matéria orgânica foi fracionada em ácidos fúlvicos e húmicos, seguindo método descrito por Stevenson (1994).

Amostras de $3,3 \mathrm{dm}^{3}$ de solo foram corrigidas com uma mistura de carbonatos de cálcio e de magnésio em uma relação molar $3: 1$, com base nos teores trocáveis de $\mathrm{Ca}, \mathrm{Mg}$ e $\mathrm{Al}$, seguindo a necessidade de calagem da Comissão Estadual de Fertilidade do Solo do Estado de Pernambuco (1998). Após quinze dias de incubação com os carbonatos a $80 \%$ da capacidade de campo, cinco doses de B $(0,0 ; 2,0 ; 4,0 ; 6,0$ e $12,0 \mathrm{mg} \mathrm{dm}^{-3}$ ) foram aplicadas às amostras utilizando como fonte o ácido bórico, seguindo-se novo período de incubação por 30 dias. Após esse período, coletaramse subamostras de $0,3 \mathrm{dm}^{3}$ de solo, para análise do B disponível por três extratores: Mehlich-1 (Embrapa, 1997), ácido clorídrico $0,05 \mathrm{~mol} \mathrm{~L}^{-1}$ (Silva \& Ferreyra H., 1998) e água quente (Berger \& Truog, 1939).

Cinco sementes de milho do cultivar AG1051 foram semeadas em vasos plásticos com $3,0 \mathrm{dm}^{3}$ de solo, em casa de vegetação. Após o desbaste, foram cultivadas duas plantas por vaso. A adubação foi parcelada aos 7 e 15 dias após a germinação, aplicando-se em cada vaso as seguintes doses de nutrientes: $50 \mathrm{mg} \mathrm{dm}^{-3} \mathrm{de}$ $\mathrm{N}\left(\mathrm{KNO}_{3}\right.$ e $\left.\left(\mathrm{NH}_{4}\right)_{2} \mathrm{SO}_{4}\right), 150 \mathrm{mg} \mathrm{dm}^{-3}$ de $\mathrm{K}\left(\mathrm{KNO}_{3} \mathrm{e}\right.$ $\left.\mathrm{K}_{2} \mathrm{SO}_{4}\right), 400 \mathrm{mg} \mathrm{dm}{ }^{-3}$ de $\mathrm{P}\left(\left(\mathrm{NH}_{4}\right)_{2} \mathrm{HPO}_{4}, \mathrm{KH}_{2} \mathrm{PO}_{4} \mathrm{e}\right.$ $\left.\mathrm{CaHPO}_{4}\right), 40 \mathrm{mg} \mathrm{dm}^{-3}$ de $\mathrm{S}\left(\mathrm{K}_{2} \mathrm{SO}_{4}\right.$ e $\left.\left(\mathrm{NH}_{4}\right)_{2} \mathrm{SO}_{4}\right)$, 3,664 mg dm${ }^{-3}$ de $\mathrm{Mn}\left(\mathrm{MnCl}_{2} 4 \mathrm{H}_{2} \mathrm{O}\right), 4 \mathrm{mg} \mathrm{dm}^{-3}$ de $\mathrm{Zn}$ $\left(\mathrm{ZnSO}_{4} 7 \mathrm{H}_{2} \mathrm{O}\right), 1,329 \mathrm{mg} \mathrm{dm}^{-3}$ de $\mathrm{Cu}\left(\mathrm{CuSO}_{4}\right)$, $1,556 \mathrm{mg} \mathrm{dm}^{-3}$ de $\mathrm{Fe}\left(\mathrm{FeSO}_{4} 7 \mathrm{H}_{2} \mathrm{O}\right)$ e $0,15 \mathrm{mg} \mathrm{dm}^{-3}$ de $\mathrm{Mo}\left(\mathrm{Na}_{2} \mathrm{MoO}_{4} 2 \mathrm{H}_{2} \mathrm{O}\right)$. Os vasos foram irrigados com água destilada duas vezes ao dia, mantendo os solos a aproximadamente $80 \%$ da capacidade de retenção de água, por meio de pesagens e reposição da água perdida por evapotranspiração. Durante o crescimento das plantas foram observados e descritos sintomas de toxidez de boro. Aos 40 dias de crescimento, a parte aérea das plantas foi coletada, seca em estufa a $70^{\circ} \mathrm{C}$ por $72 \mathrm{~h}$, pesada, moída e digerida ( $\left.\mathrm{HClO}: \mathrm{HNO}_{3}, 1: 3 \mathrm{v} / \mathrm{v}\right)$, para análise de $\mathrm{B}$

Quadro 1. Atributos químicos e físicos de solos da Zona da Mata e Agreste de Pernambuco

\begin{tabular}{|c|c|c|c|c|c|c|c|c|c|c|}
\hline Atributo (1) & PVAd & EKo & LAx & NVdf & GXve & SXe & RRd & $\mathrm{SNz}$ & LVAd & PAd \\
\hline pHágua & 5,2 & 5,1 & 4,4 & 5,5 & 5,8 & 6,4 & 4,6 & 6,4 & 3,9 & 4,5 \\
\hline $\mathrm{Ca}^{2+}\left(\mathrm{cmol}_{\mathrm{c}} \mathrm{dm}^{-3}\right)$ & 4,0 & 0,5 & 1,7 & 2,8 & 8,8 & 1,7 & 1,7 & 1,9 & 0,3 & 1,4 \\
\hline $\mathrm{Mg}^{2+}\left(\mathrm{cmol}_{\mathrm{c}} \mathrm{dm}^{-3}\right)$ & 2,8 & 0,0 & 2,0 & 2,9 & 5,8 & 0,6 & 0,6 & 2,6 & 0,0 & 0,4 \\
\hline $\mathrm{Al}^{3+}\left(\mathrm{cmol}_{\mathrm{c}} \mathrm{dm}^{-3}\right)$ & 0,1 & 0,6 & 0,5 & 0,1 & 0,0 & 0,0 & 0,9 & 0,0 & 2,1 & 1,1 \\
\hline $\mathrm{H}^{+}+\mathrm{Al}^{+}\left(\mathrm{cmol}_{\mathrm{c}} \mathrm{dm}^{-3}\right)$ & 10,2 & 4,9 & 7,9 & 5,7 & 5,4 & 1,1 & 6,2 & 1,64 & 10,5 & 11,7 \\
\hline $\mathrm{CO}\left(\mathrm{g} \mathrm{kg}^{-1}\right)$ & 27,8 & 6,7 & 22,2 & 14,0 & 15,1 & 4,7 & 13,1 & 3,4 & 22,6 & 20,2 \\
\hline Ac. Fúlvico $\left(\mathrm{g} \mathrm{kg}^{-1}\right)$ & 3,0 & 1,0 & 2,1 & 1,3 & 0,8 & 0,5 & 1,8 & 0,4 & 4,5 & 3,5 \\
\hline Ac. Húmico $\left(\mathrm{g} \mathrm{kg}^{-1}\right)$ & 3,9 & 0,9 & 1,6 & 1,1 & 1,2 & 0,7 & 2,1 & 0,2 & 2,0 & 3,3 \\
\hline Humina $\left(\mathrm{g} \mathrm{kg}^{-1}\right)$ & 5,6 & 2,0 & 4,5 & 3,4 & 4,2 & 1,5 & 2,5 & 0,7 & 3,5 & 2,5 \\
\hline $\mathrm{B}\left(\mathrm{mg} \mathrm{kg}^{-1}\right)$ & 0,28 & 0,28 & 0,65 & 0,19 & 0,65 & 0,65 & 0,65 & 0,75 & 1,20 & 1,57 \\
\hline $\mathrm{Fe}\left(\mathrm{mg} \mathrm{kg}{ }^{-1}\right)$ & 344,3 & 60,8 & 640,6 & 898,4 & 372,6 & 19,7 & 34,2 & 26,1 & 841,9 & 608,1 \\
\hline $\mathrm{Cu}\left(\mathrm{mg} \mathrm{kg}{ }^{-1}\right)$ & 0,0 & 0,0 & 0,0 & 0,0 & 0,8 & 0,0 & 0,0 & 0,0 & 0,0 & 0,0 \\
\hline $\operatorname{Mn}\left(\mathrm{mg} \mathrm{kg}^{-1}\right)$ & 22,6 & 0,0 & 0,0 & 37,0 & 52,7 & 5,8 & 52,7 & 25,5 & 0,0 & 0,0 \\
\hline Argila $\left(\mathrm{g} \mathrm{kg}^{-1}\right)$ & 294,7 & 78,1 & 479,8 & 493,1 & 536,5 & 79,8 & 164,9 & 91,4 & 317,2 & 193,1 \\
\hline Silte $\left(\mathrm{g} \mathrm{kg}^{-1}\right)$ & 138,4 & 35,1 & 64,2 & 133,9 & 91,4 & 93,3 & 151,9 & 258,3 & 56,3 & 76,7 \\
\hline Areia (g kg-1) & 566,9 & 886,8 & 455,9 & 372,9 & 372,1 & 826,8 & 683,2 & 650,2 & 626,5 & 730,2 \\
\hline
\end{tabular}

(1) Média de três réplicas. Solos: PVAd - Argissolo Vermelho-Amarelo distrófico; EKo - Espodossolo Cárbico órtico; LAx - Latossolo Amarelo coeso; NVdf - Nitossolo Vermelho distroférrico; GXve - Gleissolo Háplico Ta eutrófico; SXe - Planossolo Háplico eutrófico; RRd - Neossolo Regolítico distrófico; SNz - Planossolo Nátrico sálico; LVAd - Latossolo Vermelho -Amarelo distrófico; PAd - Argissolo Amarelo distrófico. 
segundo Bataglia (1983). Em todos os extratos obtidos no trabalho, a dosagem de $\mathrm{B}$ foi efetuada pelo método colorimétrico com o reagente azometina-H (Wolf, 1971, 1974).

O delineamento experimental foi em blocos casualizados, segundo esquema fatorial 5 x 10 (doses $\mathrm{x}$ solos), com três repetições. Os resultados foram submetidos às análises da variância, regressão e correlação com os atributos dos solos. Os níveis críticos e tóxicos de B na planta foram determinados por meio de equações de regressão, que estimaram 90 e $95 \%$ da produção máxima de matéria seca da parte aérea. Esses dois percentuais para produção de matéria seca foram adotados em razão da baixa resposta das plantas às doses de $\mathrm{B}$ em alguns solos. Para o nível tóxico, adotou-se a redução de $10 \%$ da produção máxima de matéria seca a partir da dose máxima. Nos solos, esses níveis foram determinados de forma similar, mediante equações de regressão estimando o teor de B no solo recuperado pelos extratores, considerando as doses de B aplicadas.

\section{RESULTADOS E DISCUSSÃO}

Houve efeito significativo ( $p<0,01$ ) para produção de matéria seca do milho em relação à interação doses de $\mathrm{B}$ aplicadas e solos. A produção de matéria seca foi significativamente afetada pelas doses de B em cinco dos dez solos estudados (Quadro 2). Houve melhor ajuste dos dados ao modelo quadrático no Nitossolo, Planossolo Háplico, Planossolo Nátrico e Argissolo Amarelo, enquanto para o Latossolo Amarelo o melhor ajuste foi conseguido com equação quadrática com base raiz quadrada. Similarmente ao encontrado para milho neste trabalho, baixa resposta a doses de B em alguns solos foi observada também para arroz (Fageria, 2000) e soja (Buzetti et al., 1990a).
Os níveis críticos de $\mathrm{B}$ variaram entre 0,36 e 1,40 mg kg-1 para Mehlich-1; 0,75 e 2,15 mg kg-1, para $\mathrm{HCl} 0,05 \mathrm{~mol} \mathrm{~L}^{-1}$; e 0,72 e $2,34 \mathrm{mg} \mathrm{kg}^{-1}$ para água quente (Quadro 3). Os menores níveis críticos foram obtidos para o Mehlich-1, semelhantemente ao encontrado por Mariano et al. (2000) em plantas de feijão para este extrator $\left(0,57\right.$ a $\left.1,04 \mathrm{mg} \mathrm{kg}^{-1}\right)$ e água quente $\left(0,78\right.$ e $\left.1,34 \mathrm{mg} \mathrm{kg}^{-3}\right)$. Fageria (2000) também identificou níveis críticos no solo com o extrator água quente semelhantes aos deste trabalho para milho (1,30 $\left.\mathrm{mg} \mathrm{kg}^{-1}\right)$, arroz e trigo $\left(0,40 \mathrm{mg} \mathrm{kg}^{-1}\right)$. Por sua vez, níveis críticos mais baixos $\left(0,45 \mathrm{mg} \mathrm{kg}^{-1}\right.$ para água quente e $0,56 \mathrm{mg} \mathrm{kg}^{-1}$ para $\mathrm{HCl} 0,05 \mathrm{~mol} \mathrm{~L}^{-1}$ ) foram obtidos para girassol por Silva \& Ferreyra H. (1998).

Os níveis tóxicos nos solos variaram de 1,8 a $8,3 \mathrm{mg} \mathrm{kg}{ }^{-1}$ - valores estes obtidos pelo extrator água quente. Os resultados dos níveis tóxicos do presente trabalho foram semelhantes, na maioria dos solos, aos

Quadro 2. Equações de regressão ajustadas para produção de matéria seca da parte aérea de milho (g/vaso) como variável dependente das doses de $B$ aplicadas $\left(\mathrm{mg} \mathrm{dm}^{-3}\right)$ aos solos da Zona da Mata e Agreste de Pernambuco

\begin{tabular}{|c|c|c|}
\hline Solo & Equação & $\mathbf{R}^{2}$ \\
\hline LAx & $\hat{\mathrm{Y}}=-0,805 * * \mathrm{x}+2,467 * * \mathrm{x} 0,5+13,367$ & $0,99^{*}$ \\
\hline NVdf & $\hat{\mathrm{Y}}=-0,020 * \mathrm{X}^{2}+0,384 * \mathrm{X}+19,109$ & $0,96^{*}$ \\
\hline $\mathrm{SXe}$ & $\hat{\mathrm{Y}}=-0,031{ }^{0} \mathrm{X}^{2}+0,381{ }^{0} \mathrm{x}+3,366$ & $0,69^{\circ}$ \\
\hline $\mathrm{SNz}$ & $\hat{Y}=-0,100 * x^{2}+1,043 * x+6,497$ & $0,96^{*}$ \\
\hline PAd & $\hat{\mathrm{Y}}=-0,045 * * \mathrm{x}^{2}+0,462 * * \mathrm{x}+19,747$ & $0,99^{*}$ \\
\hline
\end{tabular}

**; *, 0 Significativos a 1,5 e $10 \%$, respectivamente. Solos: LAx - Latossolo Amarelo coeso; NVdf - Nitossolo Vermelho distroférrico; Sxe - Planossolo Háplico eutrófico; SNz Planossolo Nátrico sálico; PAd - Argissolo Amarelo distrófico.

Quadro 3. Níveis críticos e tóxicos de B correspondentes a 95 e 90 \% da produção máxima de matéria seca da parte aérea de milho (em g/vaso) e redução de $10 \%$ dessa produção, estimados pelos extratores Mehlich-1, HCl 0,05 mol L $\mathrm{L}^{-1}$ água quente, em solos de Pernambuco

\begin{tabular}{|c|c|c|c|c|c|}
\hline \multirow{2}{*}{ Extrator } & \multicolumn{5}{|c|}{ Solo } \\
\hline & LAx & NVdf & SXe & $\mathrm{SNz}$ & PAd \\
\hline Mehlich-1 (95 \%) & 0,4 & 1,1 & 1,0 & 1,4 & 0,4 \\
\hline Mehlich-1 (90\%) & 0,4 & nd & 0,6 & 1,0 & nd \\
\hline Mehlich-1 (-10\%) & 2,2 & 6,2 & 3,4 & 3,2 & 4,4 \\
\hline $\mathrm{HCl}(95 \%)$ & 1,0 & 1,0 & 2,2 & 1,0 & 1,6 \\
\hline $\mathrm{HCl}(90 \%)$ & 0,9 & nd & 1,7 & 0,7 & nd \\
\hline $\mathrm{HCl}(-10 \%)$ & 3,3 & 7,2 & 4,9 & 2,4 & 5,1 \\
\hline $\mathrm{H}_{2} \mathrm{O}(95 \%)$ & 1,1 & 1,3 & 2,3 & 0,9 & 1,2 \\
\hline $\mathrm{H}_{2} \mathrm{O}(90 \%)$ & 1,0 & nd & 2,0 & 0,7 & nd \\
\hline $\mathrm{H}_{2} \mathrm{O}(-10 \%)$ & 4,9 & 8,3 & 4,4 & 1,8 & 5,9 \\
\hline
\end{tabular}

nd- não determinado. Solos: LAx - Latossolo Amarelo coeso; NVdf - Nitossolo Vermelho distroférrico; SXe - Planossolo Háplico eutrófico; SNz - Planossolo Nátrico sálico; PAd - Argissolo Amarelo distrófico. 
de Fageria (2000) em um Latossolo, onde o boro extraído com água quente apresentou teores tóxicos no solo, para trigo e milho, de 4,30 e $5,70 \mathrm{mg} \mathrm{kg}^{-1}$, respectivamente. Os diferentes níveis críticos e tóxicos apresentados neste e em outros trabalhos se devem a diferenças em características dos solos utilizados, espécie e idade das plantas, extratores e critérios adotados para o estabelecimento de tais valores. Isso corrobora a necessidade de ensaios regionalizados para determinação dos níveis críticos de $\mathrm{B}$ e do extrator adequado para avaliação da sua disponibilidade.

Na planta, os níveis críticos e tóxicos variaram entre 7,5 e 129,6 mg kg-1 e de 43,3 a $372,4 \mathrm{mg} \mathrm{kg}^{-1}$, respectivamente (Quadro 4). Esses valores podem ser relacionados à textura e, conseqüentemente, à capacidade-tampão de B nos solos. Desse modo, os menores valores críticos e tóxicos foram observados para o solo NVdf (mais argiloso), enquanto os valores mais altos foram obtidos para o solo mais arenoso (SXe). Esses dados indicam a maior disponibilidade de B, bem como a maior possibilidade de toxidez do elemento, em solos arenosos e com baixo teor de matéria orgânica. Os dados de níveis críticos de $\mathrm{B}$ obtidos neste trabalho têm caráter exploratório. Devese ressaltar, portanto, que ensaios de campo são essenciais para definição de níveis críticos do elemento.

Os dados encontrados para os níveis críticos do Nitossolo, Latossolo Amarelo e Argissolo Amarelo estão próximos dos valores considerados adequados por Fageria et al. (1997) para o milho, no qual os teores críticos de B variam de 7 a $25 \mathrm{mg} \mathrm{kg}^{-1}$. Quanto ao teor de $\mathrm{B}$ tóxico na parte aérea do milho, entre os solos, apenas o Latossolo Amarelo (49,8 $\mathrm{mg} \mathrm{kg}^{-1}$ ) e o Nitossolo (43,3 $\left.\mathrm{mg} \mathrm{kg}^{-1}\right)$ apresentaram valores próximos ao encontrado por Fageria (2000) para essa cultura (68 $\left.\mathrm{mg} \mathrm{kg}^{-1}\right)$. Buzetti et al. (1990b) determinaram nível crítico de $56 \mathrm{mg} \mathrm{kg}^{-1}$ para feijoeiro, enquanto Paula (1995) constatou que os níveis críticos de B para arroz variaram de 17 a $35 \mathrm{mg} \mathrm{kg}^{-1}$.

As equações que relacionam o $\mathrm{B}$ disponível pelos três extratores e as doses do elemento aplicadas são

Quadro 4. Níveis críticos e tóxicos de B correspondentes a 95 e 90 \% da produção máxima de matéria seca da parte aérea (em g/vaso) e redução de $10 \%$ desta produção, estimados pelos teores de $B$ em milho

\begin{tabular}{llcr}
\hline \multirow{2}{*}{ Solo } & \multicolumn{3}{c}{ Nível crítico e tóxico } \\
\cline { 2 - 4 } & $\mathbf{9 0 \%}$ & $\mathbf{9 5} \%$ & $\mathbf{- 1 0} \%$ \\
\hline & & & \\
\cline { 2 - 4 } & & $\mathrm{mg} \mathrm{kg}^{-1}$ & \\
LAx & 13,9 & 14,2 & 49,8 \\
NVdf & nd & 7,5 & 43,2 \\
SXe & 87,9 & 129,6 & 372,4 \\
SNz & 34,0 & 57,3 & 192,7 \\
PAd & nd & 26,0 & 169,0 \\
\hline
\end{tabular}

apresentadas no quadro 5. Pode-se observar que as variações nos atributos de cada solo que interferem na disponibilidade de B, especialmente teores de argila e de matéria orgânica, são refletidas nos diferentes coeficientes angulares das equações entre os solos para um mesmo extrator.

A recuperação de $B$ pelos extratores ocorreram no Latossolo Vermelho-Amarelo > Argissolo Amarelo > Neossolo, variando de $0,14 \mathrm{mg} \mathrm{kg}^{-1}$ (dose $0 \mathrm{mg} \mathrm{dm}^{-3}$ ) a $8,73 \mathrm{mg} \mathrm{kg}^{-1}$ (dose $12 \mathrm{mg} \mathrm{dm}^{-3}$ ). Considerando os resultados de cada extrator, verificou-se recuperação semelhante do micronutriente pelo Mehlich-1 e HCl $0,05 \mathrm{~mol} \mathrm{~L}^{-1}$. Os três extratores - no Espodossolo, Nitossolo e Gleissolo - recuperaram teores estatisticamente iguais $(p<0,01)$ de B. Na maioria dos casos, os valores mais elevados de $\mathrm{B}$ recuperado foram obtidos pelo método da água quente, enquanto os menores foram obtidos pelo ácido clorídrico. Chaudhary \& Shukla (2004) também obtiveram maiores extrações com água quente entre sete extratores utilizados.

Devido à maior disponibilidade de $\mathrm{B}$ relacionada à textura arenosa e, ou, ao baixo teor de matéria orgânica (Quadro 1), as plantas cultivadas no Planossolo Háplico, Planossolo Nátrico e Neossolo exibiram sintomas mais nítidos de toxidez do

Quadro 5. Equações de regressão ajustadas entre o B recuperado pelos três extratores ( $\hat{y}$ em mg kg-1) como variável dependente das doses desse micronutriente aplicadas $\left(x \mathrm{em} \mathrm{mg} \mathrm{dm}^{-3}\right.$ ) aos solos da Zona da Mata e Agreste de Pernambuco

\begin{tabular}{|c|c|c|}
\hline Solo & Equação & $\mathbf{R}^{2}$ \\
\hline \multicolumn{3}{|c|}{ Mehlich-1 } \\
\hline LAx & $\hat{\mathrm{Y}}=0,217 * * * \mathrm{x}+0,357$ & $0,99 * * *$ \\
\hline NVdf & $\hat{\mathrm{Y}}=0,294 * * * \mathrm{x}+0,476$ & $0,98^{* * *}$ \\
\hline SXe & $\hat{\mathrm{Y}}=0,373 * * * \mathrm{x}+0,285$ & $0,98^{* *}$ \\
\hline $\mathrm{SNz}$ & $\hat{\mathrm{Y}}=0,367 * * * \mathrm{x}+0,031$ & $0,99 * * *$ \\
\hline PAd & $\hat{\mathrm{Y}}=0,348 * * * \mathrm{x}+0,287$ & $0,97^{* *}$ \\
\hline \multicolumn{3}{|c|}{$\mathrm{HCl} 0,05 \mathrm{~mol} \mathrm{~L}^{-1}$} \\
\hline LAx & $\hat{\mathrm{Y}}=0,277^{* * *} \mathrm{X}+0,909$ & $0,97^{* *}$ \\
\hline NVdf & $\hat{\mathrm{Y}}=0,354 * * * \mathrm{X}+0,205$ & $0,99 * * *$ \\
\hline SXe & $\hat{\mathrm{Y}}=0,417 * * * \mathrm{x}+0,718$ & $0,99 * * *$ \\
\hline $\mathrm{SNz}$ & $\hat{\mathrm{Y}}=0,278^{* *} \mathrm{x}+0,143$ & $0,97^{* *}$ \\
\hline PAd & $\hat{\mathrm{Y}}=0,295^{* *} \mathrm{x}+1,553$ & $0,95^{* *}$ \\
\hline \multicolumn{3}{|c|}{ Água quente } \\
\hline LAx & $\hat{\mathrm{Y}}=0,467 * * * \mathrm{X}+0,962$ & $0,99 * * *$ \\
\hline NVdf & $\hat{\mathrm{Y}}=0,405 * * * \mathrm{x}+0,375$ & $0,99 * * *$ \\
\hline SXe & $\hat{\mathrm{Y}}=0,319 * * * \mathrm{x}+1,242$ & $0,97^{* *}$ \\
\hline $\mathrm{SNz}$ & $\hat{\mathrm{Y}}=0,181 * * * \mathrm{x}+0,325$ & $0,98^{* * *}$ \\
\hline PAd & $\hat{\mathrm{Y}}=0,410 * * * \mathrm{X}+1,031$ & $0,99 * * *$ \\
\hline
\end{tabular}

***; ** Significativos a 0,1 e $1 \%$, respectivamente. Solos: LAx - Latossolo Amarelo coeso; NVdf - Nitossolo Vermelho distroférrico; SXe - Planossolo Háplico eutrófico; SNz Planossolo Nátrico sálico; PAd - Argissolo Amarelo distrófico. 
micronutriente, principalmente nas doses de 6 e $12 \mathrm{mg} \mathrm{dm}^{-3}$. De forma geral, os sintomas foram caracterizados por manchas marrons necróticas nas margens das folhas mais velhas, as quais se estenderam às folhas mais novas com o desenvolvimento das plantas. As plantas no Espodossolo, Latossolo Amarelo e Neossolo, além dos Planossolos, que apresentaram a maior redução na produção de matéria seca, exibiram ainda caules bastante delgados em comparação aos das plantas dos demais solos. Sintomas semelhantes de toxidez de B foram descritos por outros autores para outras culturas: tomate (Ben-Gal \& Shani, 2002), melão (Goldberg et al., 2002), cevada (Torun et al., 2003), pepino (Aspaslan \& Gunes, 2001) e soja (Furlani et al., 2001).

No quadro 6 são apresentadas as correlações entre B disponível recuperado pelos extratores e características dos solos e da planta. Observou-se maior coeficiente de correlação entre teor de B na planta e o teor extraído com $\mathrm{HCl}$ 0,05 mol L-1. Este extrator, porém, apresentou a menor correlação com o conteúdo de B na parte aérea. O teor de B extraído com Mehlich-1 apresentou a segunda melhor correlação $\left(0,55^{* * *}\right)$ com o teor de B na parte aérea do milho, sendo esse resultado semelhante àquele encontrado por Bataglia \& Raij (1989) para o teor de B do girassol estimado por Mehlich-1 (0,52). Esses autores encontraram ainda coeficientes de correlação de 0,78 e 0,40 com o uso da água quente, para as culturas do girassol e sorgo, respectivamente.

Quanto aos atributos dos solos, o teor de $\mathrm{B}$ com $\mathrm{HCl}$ $0,05 \mathrm{~mol} \mathrm{~L}^{-1}$ apresentou as maiores correlações com carbono orgânico, ácidos fúlvicos e húmicos. Os coeficientes positivos com o carbono orgânico indicam que parte do B ligado aos colóides orgânicos encontrase disponível à absorção pelas plantas. Por outro lado, os ácidos fúlvicos e húmicos apresentaram coeficientes de correlação negativos e altamente significativos com o B pelo $\mathrm{HCl}$ 0,05 mol L-1. Essas frações da matéria orgânica humificada podem ter papel importante na adsorção de B (Parks \& White, 1952), por meio da ligação do micronutriente aos grupos carboxílicos dos ácidos do húmus (Gu \& Lowe, 1990). No presente estudo, no entanto, não foi obtida correlação significativa entre ácidos fúlvicos e húmicos e teor de $\mathrm{B}$ nas plantas. Quanto à argila, apenas o $\mathrm{B}$ extraído com Mehlich-1 apresentou coeficiente negativo, indicando ser a disponibilidade de B sensível ao teor de argila (capacidade-tampão de B no solo), corroborado pela correlação negativa $\left(-0,45^{* *}\right)$ entre teor de B na parte aérea e teor de argila dos solos.

\section{CONCLUSÕES}

1. Os níveis críticos e tóxicos de $\mathrm{B}$ nos solos obtidos em casa de vegetação variaram de 0,4 a $2,3 \mathrm{mg} \mathrm{kg}^{-1} \mathrm{e}$ de 1,8 a $8,3 \mathrm{mg} \mathrm{kg}^{-1}$, respectivamente. Nas plantas de milho, os níveis críticos variaram de 13,8 a $129,6 \mathrm{mg} \mathrm{kg}{ }^{-1}$, enquanto os teores tóxicos foram obtidos entre 43,3 e $372,2 \mathrm{mg} \mathrm{kg}^{-1}$.

2. A melhor correlação entre o teor de B na planta e o B no solo foi observado ao se utilizar $\mathrm{HCl} \mathrm{0,05} \mathrm{mol} \mathrm{L}^{-1}$, seguido pelo Mehlich-1 e pela água quente. A disponibilidade do $\mathrm{B}$ no solo pelo extrator $\mathrm{HCl}$ e os teores de $\mathrm{B}$ na folha foram afetados negativamente pelo aumento no teor de argila e matéria orgânica dos solos.

3. Plantas com maior teor de B no tecido vegetal mostraram sintomas mais graves de toxidez, fato associado à maior disponibilidade desse micronutriente naqueles solos com textura mais arenosa e, ou, baixo teor de matéria orgânica.

\section{LITERATURA CITADA}

ASPASLAN, M. \& GUNES, A. Interactive effects of boron and salinity stress on the growth, membrane permeability and mineral composition of tomato and cucumber plants. Plant Soil, 236:123-128, 2001

Quadro 6. Coeficientes de correlação linear simples entre B recuperado $\left(\mathrm{mg} \mathrm{kg}^{-1}\right)$ pelos extratores e características da planta e dos solos de Pernambuco utilizados no experimento

\begin{tabular}{|c|c|c|c|}
\hline \multirow{2}{*}{ Característica } & \multicolumn{3}{|c|}{ Extrator } \\
\hline & Mehlich-1 & $\mathrm{HCl} 0,05 \mathrm{~mol} \mathrm{~L}^{-1}$ & Água Quente \\
\hline Teor de B na planta (mg kg-1) & $0,55^{* * *}$ & $0,70 * * *$ & $0,51 * * *$ \\
\hline Conteúdo de B na parte aérea (mg/vaso) & $0,73 * * *$ & $0,69 * * *$ & $0,71 * * *$ \\
\hline Carbono orgânico (g kg-1) & $\mathrm{ns}$ & $0,61 * * *$ & $0,43 * * *$ \\
\hline Argila $\left(\mathrm{g} \mathrm{kg}^{-1}\right)$ & $-0,42 * *$ & $\mathrm{~ns}$ & $0,39 * *$ \\
\hline Ác. fúlvico (g kg-1) & $0,30 *$ & $-0,46 * * *$ & $0,34 * *$ \\
\hline Ác. húmico (g kg-1) & $\mathrm{ns}$ & $-0,52 * * *$ & $0,27^{*}$ \\
\hline
\end{tabular}

$* * *, * *, *,{ }^{0}$ ens. Significativos a $0,1,1$ e $5 \%$ e não-significativo, respectivamente. 
BATAGLIA, O.C. Métodos de análise química de plantas. Campinas, Instituto Agronômico, 1983. 48p.

BATAGLIA O.C. \& RAIJ, B. van. Eficiência de extratores de micronutrientes na análise de solo. R. Bras. Ci. Solo, 13:205-212, 1989.

BEN-GAL, A. \& SHANI, U. Yield, transpiration and growth of tomatoes under combined excess boron and salinity stress. Plant Soil, 247:211-221, 2002.

BERGER, K.C. \& TRUOG, E. Boron determination in soils and plants. Ind. Eng. Chem., 11:540-545, 1939.

BUZETTI, S.; MURAOKA, T. \& SÁ, M.E. Doses de boro na soja, em diferentes condições de acidez do solo: I. Produção de matéria seca e de grãos e nível crítico no solo. R. Bras. Ci. Solo, 14:157-161, 1990a.

BUZETTI, S.; MURAOKA, T. \& SÁ, M.E. Doses de boro na soja, em diferentes condições de acidez do solo: II. Níveis críticos na planta e nos grãos. R. Bras. Ci. Solo, 14:163$166,1990 \mathrm{~b}$.

CHAUDHARY, D.R. \& SHUKLA, L.M. Evaluation of extractantes for predicting availability of boron to mustard in arid soils of India. Comm. Soil Sci. Plant Anal., 35:267-283, 2004.

EMPRESA BRASILEIRA DE PESQUISA AGROPECUÁRIAEMBRAPA. Manual de métodos de análise de solo. 2. ed. Rio de Janeiro, Centro Nacional de Pesquisas de Solos, 1997. 212p.

COMISSÃO ESTADUAL DE FERTILIDADE DO SOLO DE PERNAMBUCO - CEFS/PE. Recomendação de adubação para o estado de Pernambuco: $2^{\mathrm{a}}$ aproximação. Recife, IPA, 1998.

FAGERIA, N.K.; BALIGAR, V.C. \& JONES, C.A. Growth and mineral nutrition of field crops. 2. ed. New York, Marcel Dekker, 1997. 656p.

FAGERIA, N.K. Níveis adequados e tóxicos de boro na produção de arroz, feijão, milho, soja e trigo em solo de cerrado. R. Bras. Eng. Agr. Amb., 4:57-62, 2000.

FURLANI, A.M.C.; TANAKA, R.T.; TARALLO, M.; VERDIAL, M.F. \& MASCARENHAS. H.A.A. Exigência a boro em cultivares de soja. R. Bras. Ci. Solo, 25:929-937, 2001.

GOLDBACH, H.E.; YU, Q.; WINGENDER, R.; SCHULZ, M.; WIMMER, M.; FINDEKLEE, P. \& BALUSKA, R. Rapid response reactions of roots to boron deprivation. J. Plant Nut. Soil Sci., 164:173-181, 2001.

GOLDBERG, S. \& GLAUBIG, R.A. Boron adsorption on aluminum and iron oxide minerals. Soil Sci. Soc. Am. J., 49:1374-1379, 1985.

GOLDBERG, S. \& FORSTER, H.S. Boron sorption on calcareous soils and reference calcites. Soil Sci., 152:304310, 1991.
GOLDBERG, S. Reanalysis of boron adsorption on soils and soil minerals using the constant capacitance model. Soil Sci. Soc. Am. J., 63:823-829, 1999.

GOLDBERG, S.; SHOUSE, P.J.; LESCH, W.M.; GRIEVE, C.M.; POSS, J.A.; FORSTER, H.S. \& SUAREZ, D.L. Soil boron extractions as indicators of boron content of field-grown crops. Soil Sci., 167:720-728, 2002.

GU, B. \& LOWE, L.E. Studies on the adsorption of boron on humic acids. Can. J. Soil Sci., 70:305-311, 1990.

GUPTA, U.C. Boron and its role in crop production. Charlottetown, CRC Press, 1993. 237p.

MARIANO, E.D.; FAQUIN, V.; NETO, A.E.F.; ANDRADE, A.T. \& MARIANO, I.O. Níveis críticos de boro em solos de várzea para o cultivo do feijoeiro. Pesq. Agropec. Bras., 35:1637-1644, 2000.

NABLE, R.O.; BAÑUELOS, G.S. \& PAULL, J.G. Boron toxicity. Plant Soil, 193:181-198, 1997.

PARKS, W.L. \& WHITE, J.L. Boron retention by clay and humus systems saturated with various cations. Soil Sci. Soc. Am. Proc., 16:298-300, 1952.

PAULA, M.B. Eficiência de extratores e níveis críticos de boro disponível em amostras de solos aluviais e hidromórficos sob a cultura do arroz inundado. Lavras, Universidade Federal de Lavras, 1995. 69 p. (Tese de Doutorado)

ROCHA, G.C. Micronutrientes nos solos do Brasil. Semina, 16:158-168, 1995.

SHORROCKS, V.M. The occurrence and correction of boron deficiency. Boron Agric., 17:3-5, 1997.

RÖMHELD, V. Aspectos fisiológicos dos sintomas de deficiência e toxicidade de micronutrientes e elementos tóxicos em plantas superiores. In: FERREIRA, M.E.; CRUZ, M.C.P.; RAIJ, B. van \& ABREU, C.A. Micronutrientes e elementos tóxicos na agricultura. Jaboticabal, 2001. p.71-85.

SILVA, F.R. \& FERREYRA H., F.F. Avaliação de extratores de boro em solos do estado do Ceará. R. Bras. Ci. Solo, 22:471478,1998 .

STEVENSON, F.J. Humus chemistry: genesis, composition, reaction. New York, Willey Interscience, 1994. 443p.

TORUN, B.; KALAYCI, M.; OZTURK, L.; TORUN, A.; AYDIN, M. \& CARMAK, I. Differences in shoot boron concentrations, leaf symptoms, and yield of Turkish barley cultivars grown on boron-toxic soil in field. J. Plant Nut., 26:1735-1747, 2003.

WOLF, B. The determination of boron in soil extracts, plant materials, composts, water and nutrient solutions. Comm. Soil Sci. Plant Anal., 2:363-374, 1971.

WOLF, B. Improvents in the azomethine-H method for determination of boron. Comm. Soil Sci. Plant An., 5:3944, 1974. 